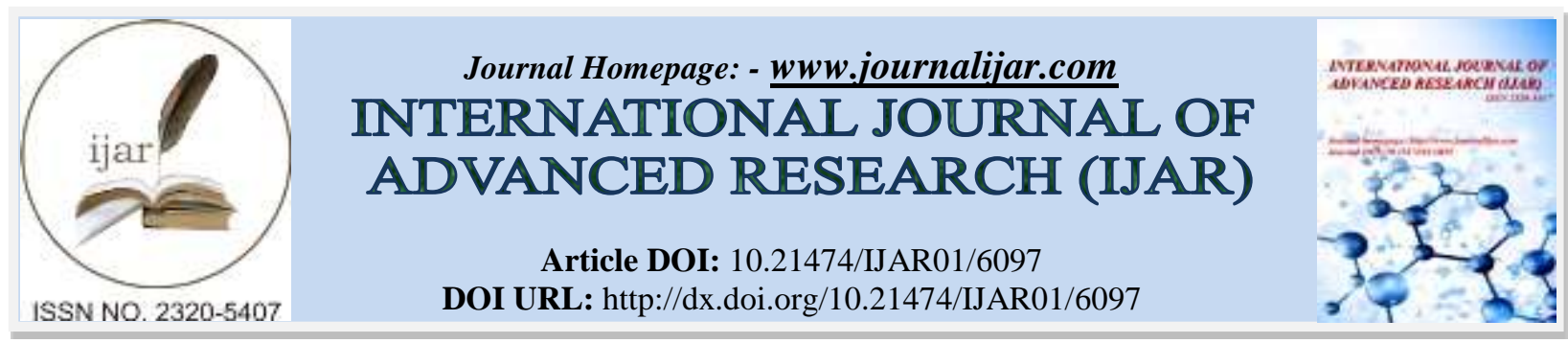

RESEARCH ARTICLE

\title{
DO PARENTAL EDUCATION AND OCCUPATION AFFECTS CHILDREN'S BODY MASS INDEX (BMI)?
}

Fahad Alqarni, Mohammed Alariefy, Abdulrahman Albishri, Ahmed Bajubair, Adel Almuzaini, Emad Alzahrani and Waleed Bandar.

\section{Manuscript Info}

Manuscript History

Received: 18 October 2017

Final Accepted: 18 November 2017

Published: December 2017

Keywords:-

Childhood; Obesity; Parents; occupation; Education.

\begin{abstract}
Objective: To investigate the association between the parental education and occupation and their effects on childhood obesity. Methods: This cross-sectional retrospective study was conducted in Jeddah, Saudi Arabia in 2017. The data were collected from children and adolescents aged 2-18 years old. The participants were directed to an ambulatory clinic in King Abdul-Aziz Hospital for executing anthropometric measurements. Results: Of the total 328 participants 170 were male children and 158 were female children. The prevalence rates of overweight, obese and severely obese children were 139, 160 and 29 respectively. It is identified in this study that those children were more to be obese if they had employed fathers (93.3\%) with pvalue $=(0.031)$ and non-working mothers $(55.7 \%)$ with $\mathrm{p}$-value $=$ (0.047). It is identified that there was no significant relation between BMI categories and father's education level $(\mathrm{P}$-value $=0.226, \rho=$ 0.059 ) and mother's education (P-value $=0.291, \rho=0.052)$. Conclusion: Overweight and obesity among children living in Jeddah, Saudi Arabia is not associated with the educational levels of both parents, however, it is also identified that overweight and obesity were associated with employed father and non-employed mothers.
\end{abstract}

Copy Right, IJAR, 2017,. All rights reserved.

\section{Introduction:-}

Obesity among children and adolescent is one of the most common medical problems in the world. Obesity is defined as an excessive accumulation of fat in the body. According to World Health Organization (WHO), the number of obese or overweight children under the age of 5 years in 2014 was about 41 million [1]. A study conducted in Saudi Arabia in 2012 estimated the prevalence of overweight and obesity among students aged 6-13 years old to be $7.3 \%$ and $17.4 \%$, respectively in male students, while in female students the prevalence was $12.4 \%$ and $20.9 \%$, respectively [2]. Another research study conducted in Saudi Arabia showed an increased prevalence of obesity among primary-school boys aged 6-14 years old from $3.4 \%$ to $24.5 \%$ between the time period of 1988 to 2005 [3]. It is articulated that many health problems in children and adolescents are associated with obesity such as diabetes mellitus type $2[4,5]$, cardiovascular diseases, and depression [6]. Multiple factors are associated with the development of obesity including genetic [7], metabolic, social and familial factors [8]. The association of parental education and occupation with children and adolescent obesity were observed before in several studies but still, there are not enough studies correlating parental education and occupation with child and adolescent obesity especially in Saudi Arabia. A study conducted in Egypt showed that obesity is more common among children with 
non-working mothers than children with working and overweight mothers and fathers with high education [9]. Another study in Germany showed a significant relationship between childhood obesity and parental education, children of mothers who had no degree had more risk to be obese than mothers with school degree [10]. The aim of this study was to determine the relationship between parental education and occupation and children and adolescent obesity in Jeddah, Saudi Arabia.

\section{Methodology:-}

A retrospective cross-sectional study was conducted in various ambulatory clinics at King Abdul-Aziz University Hospital, Jeddah, and KSA. Ambulatory clinics are characterized as the outpatient healthcare facilities that cater primary healthcare needs of a localized population. The aim of this study is to investigate the association between the parental education and occupation and their effects on childhood obesity. The duration of the study is 4 months during the period from May 2017 through September 2017. This study was conducted under approval by the Research Ethics Cat King Abdul-Aziz University Hospital.

\section{Participants:-}

An electronic questionnaire was distributed in order to attain sample size of 328 children. 170 (51.8\%) of the sample were males and $158(48.2 \%)$ were females that were randomly chosen through simple random sampling technique. Healthy children and adolescents according to their BMI aged between 2-18 years old are included in the study. The exclusion criteria were a child on dietary intervention, BMI $85^{\text {th }}<$, exposure to hormonal therapy, development of secondary obesity due to endocrinopathies, serious intercurrent illness. Moreover, incomplete questionnaires with insufficient data were also excluded.

\section{Instruments:-}

The weight, height, waist and hip circumference were measured to the nearest centimeters. Subjects were asked to remove their shoes and wear minimal clothes before the measurement. The weight was measured by using a single scale, which was re-calibrated for every new subject. The height of subject was measured by using a mechanical beam scale with a height rod with the shoulders in a relaxed position and arms hanging freely. Their waist and hip circumference were measured by using a measuring tape. All the previously mentioned anthropometric measurements were plotted on the chart and measured thrice and the mean was selected. BMI (weight in kg divided by height in square meters) was calculated and the children were classified as either overweight $\left(85^{\text {th }}-95^{\text {th }}\right)$, obese $\left(96\right.$ th $\left.-99^{\text {th }}\right)$, severely obese $\left(>99^{\text {th }}\right)$. Children BMI percentile was calculated specifically for age and sex based on the Center for Disease Control and Prevention (CDC) growth charts.

\section{Data collection:-}

Data were collected by questionnaires filled out using tablet devices during a face-to-face interview. In addition, medical records of the respondents were also reviewed to exclude any medical conditions that will affect the child's BMI. The questionnaire included questions about demographics, dietary habits, physical activity, parental education, occupation, and family income. The parental education level was classified into 4 groups: illiterate, high school and below, Bachelor`s degrees and postgraduate. Parental occupation was classified into employed or non-employed. Employment of parents was classified into professional or manual work. Parents were asked to identify the time spent by their children in watching TV and consumption of junk food by their children. Moreover, parents were also asked regarding the physical activity of their child; physical activities were classified into sedentary, moderate, or high activity. An informed verbal consent was acquired from both the parents and children. Some results were excluded from the study as there was missing information related to different questions including BMI, physical activity, mother's, and/or father's education level.

\section{Definitions:-}

According to the financial status of the population, lower economic status is attributed to the monthly income below 5000 Saudi Riyals. Middle economic status is attributed to the monthly income, which ranges from 6000 to 10000 Saudi Riyals. Higher economic status is defined as the monthly income more than 10000 Saudi Riyals. Regarding education for both parents, illiterates characterize those Degree or $\mathrm{Ph} . \mathrm{D}$. In addition to these questions, parents were also inquired about junk food. Junk food is considered as the type of food that is high in calories usually due to excessive sugar, salt, fat and small amount of nutritional value. They include (fast food, sweetened beverages, candy, salted crisps, and so forth). 


\begin{tabular}{|l|l|l|l|l|}
\hline Variable & $\begin{array}{l}\text { Overweight } \\
\text { number of patient }(\%)\end{array}$ & $\begin{array}{l}\text { Obese } \\
\text { number of patient } \\
(\%)\end{array}$ & $\begin{array}{l}\text { Severe Obesity } \\
\text { number of patient } \\
(\%)\end{array}$ & Total \\
\hline $\begin{array}{l}\text { Gender } \\
\text { Male }\end{array}$ & $72(51.8)$ & $85(53.1)$ & $13(44.8)$ & $170(51.8)$ \\
Female & $67(48.2)$ & $75(46.9)$ & $16(55.2)$ & $158(48.2)$ \\
\hline Age (years) & $35(25.2)$ & $24(15.0)$ & $3(10.3)$ & $62(18.9)$ \\
$<6$ & $56(40.3)$ & $65(40.6)$ & $14(48.3)$ & $135(41.1)$ \\
$6-12$ & $48(34.5)$ & $71(44.4)$ & $12(41.4)$ & $131(40)$ \\
$>12$ & & & \\
\hline
\end{tabular}

Table 1:- Demographic data in relation to BMI level groups

Data variables: Various environmental factors were reviewed including; Physical daily activity, consumption of junk food, time spent on TV watching. In addition to that, we reviewed the educational level of parents, socioeconomic status, and marital status of parents, geographical distribution of parents and place of residency are also reviewed by the researchers.

\section{Statistical Analysis:-}

Statistical analysis was executed by a well-qualified statistician. Moreover, the entire results are demonstrated in numerical forms. P-value is considered of significant value if obtained less or equal to 0.05. Entire data was entered, coded and analyzed with the execution of different statistical tests. Statistical analyses were conducted using SPSS, version 22. The analysis was done by testing the significant relationship between parent's education, occupation and income levels with their children BMI level by using Spearman correlation test for ordinal variables. Also, the relation between children's BMI levels with (eating habits and lifestyle) were tested. BMI ranges categorized depends on percentile scales such as 3rd Percentile (Underweight), 5th Percentile (Healthy weight), 85th Percentile (Overweight) and 95th Percentile (Obese).Simple descriptive statistics are reported as proportions for qualitative variables such as frequencies and percentages of the prevalence of obesity also clarified family socioeconomic status and child's eating habits. The results were considered too significant with $\mathrm{p}$ (less than) 0.05 and sometimes with $\mathrm{p}$ (less than) 0.01 .

\section{Results:-}

Of the 328 children and adolescents who participated in this study, 158 were females and 170 were male. Table 1 depicts demographics data of participants according to the BMI levels. Patients who were under 6 years were 62(19.0\%), while who were between 6 to 12 years were 135(41.1\%), 131(40\%) were above 12 years. It is also identified that $139(42.3 \%)$ of the total participants possess overweight BMI, while $160(48.7 \%)$ of the total participants were identified as obese and $29(9.0 \%)$ were identified as severely obese. 
Table 2:-The statistical test results related to parent occupation according to BMI.

\begin{tabular}{|c|c|c|c|c|}
\hline Variable & overweight & obese & sever obesity & $\mathrm{p}$-value \\
\hline $\begin{array}{l}\text { Level of education father } \\
\text { Illiterate } \\
\text { High school and below } \\
\text { Bachelor's degree } \\
\text { Postgraduate }\end{array}$ & $\begin{array}{l}10(7.2) \\
43(30.9) \\
69(49.6) \\
17(12.2) \\
\end{array}$ & $\begin{array}{l}7(4.4) \\
52(32.5) \\
83(51.9) \\
18(11.3) \\
\end{array}$ & $\begin{array}{l}1(3.4) \\
6(20.7) \\
16(55.2) \\
6(20.7)\end{array}$ & 0.226 \\
\hline $\begin{array}{l}\text { Level of education mother } \\
\text { Illiterate } \\
\text { High school and below } \\
\text { Bachelor's degree } \\
\text { Postgraduate }\end{array}$ & $\begin{array}{l}10(7.2) \\
73(52.5) \\
51(36.7) \\
5(3.6) \\
\end{array}$ & $\begin{array}{l}15(9,4) \\
70(44.0) \\
69(43.4) \\
5(3.1) \\
\end{array}$ & $\begin{array}{l}1(3.4) \\
11(37.9) \\
14(48.3) \\
3(10.3) \\
\end{array}$ & 0.291 \\
\hline $\begin{array}{l}\text { Father occupation } \\
\text { Employment } \\
\text { Non employment }\end{array}$ & $\begin{array}{l}126(90.6) \\
13(9.4)\end{array}$ & $\begin{array}{l}151(94.4) \\
9(5.6)\end{array}$ & $\begin{array}{l}29(100) \\
0(0)\end{array}$ & 0.031 \\
\hline $\begin{array}{l}\text { Mother occupation } \\
\text { Employment } \\
\text { Non employment }\end{array}$ & $\begin{array}{l}55(39.6) \\
84(60.4)\end{array}$ & $\begin{array}{l}75(46.9) \\
85(53.1) \\
\end{array}$ & $\begin{array}{l}15(51.7) \\
14(48.3)\end{array}$ & 0.047 \\
\hline $\begin{array}{l}\text { Family Income } \\
\text { high } \\
\text { middle } \\
\text { low }\end{array}$ & $\begin{array}{l}58(41.7) \\
68(48.9) \\
13(9.4)\end{array}$ & $\begin{array}{l}70(43.8) \\
71(44.4) \\
19(11.9)\end{array}$ & $\begin{array}{l}17(58.6) \\
11(37.9) \\
1(3.4)\end{array}$ & 0.039 \\
\hline
\end{tabular}

\section{Parental education and occupation:-}

In order to identify the parental education and occupation status, parents were asked to identify their education and occupation as according to the classification provided in the questionnaire. It is identified that 18 (5.5\%) of the fathers were illiterate, $101(31.0 \%)$ belongs to the high school and below class, $168(51 \%)$ possess bachelor's degrees, and $41(12.5 \%)$ were postgraduate. On the other hand, results also identified that $26(8.0 \%)$ of the mothers were illiterate, $154(47.0 \%)$ belongs to the high school and below educational status, $134(41.0 \%)$ possess bachelor's degrees, and $13(4.0 \%)$ were postgraduate. It can be identified through results that there was no significant relationship between BMI categories and father's education level and mother's education. Table 2 depicts parental education level according to BMI.

Occupation status results of parents indicate that 306 (93.3\%) of fathers were employed and $22(7.7 \%)$ were not employed. Moreover, it is also identified that there was a significant relationship between BMI categories and father's occupation. Analyzing the results indicate that father of most of the overweight and obese children were employed. On the other hand, maternal results indicate that the $145(44.3 \%)$ of the mothers were employed and 183 $(55.7 \%)$ were not employed. It is identified through a statistical test that there was a significant relationship between BMI categories and mother's occupation. Mothers of most of the overweight and obese children were not employed. Table 2 depicts the statistical test results related to parent occupation according to BMI.

\section{Family Income:-}

Results indicate that $145(44.2 \%)$ of total respondents possess high-income level; $150(45.7 \%)$ of the total participants belong to a middle-income level group and 33(10.1\%) of the total respondents belong to lower income level. The negative significant relation was identified between BMI categories and income levels. It was also identified that most of the overweight and obese children belongs to the higher or middle family income level. The p-value and family income according to BMI are summarized in table 2 . 


\section{Obesity:-}

Through attained results, it is identified that obesity was associated with lack of physical activity of the children (pvalue $=0.047$ ). It was identified by the majority of the respondents that their children are involved in physical activities 2 to 4 times per week. Moreover, $108(25.9 \%)$ of the total respondents indicated that their children are involved in physical activities on daily basis, 103(24.7\%) indicate that their children are occasionally involved in physical activities and $85(20.4 \%)$ indicate that their children have physical activities only once in the entire week. It is also identified that obesity is also associated with time spent in watching television ( $\mathrm{p}$-value $=0.01$ ). Results indicate that $112(27.1 \%)$ parents identified that their children spent less than two hours in watching TV, $192(46.4 \%)$ respondents indicate that their children spent two to four hours in watching television; $110(26.5 \%)$ indicate that their children spent more than four hours in watching television.

Through results, it is also identified that obesity was also associated with increased consumption of junk food by the children. It is identified that Majority of the parents $(150,36.1 \%)$ identified that their children consume junk food on daily basis. $113(27.2 \%)$ indicate that their children consume junk food two to four time per week, 102 (24.6\%) indicate that their children occasionally consume junk food and only 50 respondents (12\%) indicate that their children consume junk food only once in a week.

\section{Discussion:-}

Several studies have been conducted and have confirmed the rising prevalence of obesity among the children of Saudi Arabia, while several other international studies have shown a causal link between parental education, occupation, food prices, access to fast food and school nutrition policies on childhood obesity. Yet, such exact causes cannot always explain the excess variation within regions or races groups. This study revealed the alarmingly high prevalence of childhood obesity in Jeddah as compare to other cities of Saudi Arabia and other countries. Moreover, this research study also evaluated the relationship between parental education and occupation with childhood obesity.

\begin{tabular}{|l|l|ll|lc|}
\hline & Category & Frequency & percent & (p-value) & $\rho$ \\
\hline Physical Activity of the Child & (2 to 4) times & 121 & $29 \%$ & 0.047 & -0.097 \\
& per week daily. & 108 & $25.9 \%$ & & \\
& Occasionally & 103 & $24.7 \%$ & & \\
& once weekly & 85 & $20.4 \%$ & & \\
\hline Time spent watching TV & $<2$ hours & 112 & $27.1 \%$ & 0.01 & 0.116 \\
& $2-4$ hours & 192 & $46.4 \%$ & & \\
& $>$ 4 hours & 110 & $26.5 \%$ & & \\
& & & & & \\
\hline Consumption of junk food & (2 to 4) times & 113 & $27.2 \%$ & 0.0001 & 0.370 \\
& per week & 150 & $36.1 \%$ & & \\
& Daily. & 102 & $24.6 \%$ & & \\
& Occasionally & 50 & $12 \%$ & & \\
& once weekly & & & & \\
\hline
\end{tabular}

Table 1:- Obesity and related factors

\section{Parental education:-}

It is identified in this study that there was no association between obesity and parental occupation and education. It is found through statistical results that father's educational level had no significant increase on the mean BMI (pvalue $=0.226$ ), likewise, mother's educational level also had no significant increase on the mean BMI ( $\mathrm{p}$ value $=0.291$ ). A study was conducted in Saudi Arabia during the period of January to March that integrates a sample size of 2239 female schoolchildren. In this research study, a chi-square test was used in order to test the significance of the association between body max index and socioeconomic variables. It is identified that the prevalence of overweight and obesity were $20 \%$ and $11 \%$ respectively. In this research study, it is identified that children of highly educated mothers were overweight and obese as compared to the children of mothers who are less educated [11].

Another cross-sectional study conducted in Kuwait with a sample size of 3473 children indicate that parent's educational level was found to be significantly associated with overweight and obesity [12]. In another study, a random sample of 512 children aged from 4 to 14 was selected to study the correlation between overweight and 
educational level of the parents in Denmark. In this research study, it is identified that parents with high educational level were significantly associated with overweight [13]. In addition, 3166 children in Norway were included in a study that showed children of low educated mothers had an increase in mean BMI $(p$-value $=.01)$, whereas corresponding trends for children who had mothers with higher educational background were non-significant ( $\mathrm{p}$ value $=>0.30$ ) [14]. In contrast, a study with a sample of 3636 children conducted in Sweden showed the prevalence of overweight was $15.6 \%$ and $2.6 \%$ out of them were obese with an association with high maternal education [15]. Another study with a sample of 1860 children conducted in Pakistan showed a significant correlation between overweight and obesity with higher parental education $(p$-value $=0.001)[16]$.

\section{Occupation:-}

In this study, it is identified that the fathers who are employed were significantly associated with childhood obesity ( $\mathrm{p}$-value $=0.031$ ). Two studies conducted in Kuwait and Australia demonstrate that father's socioeconomic status has an impact on the household dietary values and physical activity $[17,18]$. The results of the current study indicate that there is a significant association between childhood obesity and the non-working mothers ( $\mathrm{p}$-value $=0.047$ ), on the other hand, it is identified that obesity is insignificantly associated with working mothers. From the literature search, it can be noticed that there exist a relationship between working mothers and having obese children [19, 20]. This can be explained by the parent's long absence from home that leads the children to be exposed to unhealthy dietary habits of fast food, snacks and skipped meals. Other studies conducted in developed countries found a significant association between obesity and working status of the mother as the child is more likely to be overweight if the mother works more hours per week during childhood that impede young children's access to healthy foods and physical activity [21].

\section{Family income :-}

In addition to that, data of the current study showed that the risk of becoming overweight and obese among Saudi children tends to be greater with higher family income. This association between obesity and higher socioeconomic status has been observed in two studies conducted with the context of Saudi Arabia. A study conducted in Saudi Arabia determined the prevalence of obesity among school-girls in a high-class district in Riyadh and found an obesity occurrence of $14.9 \%$ [22]. Another study conducted in Saudi Arabia with a targeted children aged 10-14 years old indicate that $9.7 \%$ of them were obese and $14.2 \%$ were overweight [23]. Consequently, most of the parents in Saudi Arabia usually depends on foreign caregivers or housemaids to take care of their children.

A study was executed in Saudi Arabia to evaluate the Saudi families that depend on caregivers and it showed that $89 \%$ of Saudi families have at least one servant, $79 \%$ of the servant were non-Arabic origin [24]. This may reduce the chances of parent's supervision and control on their children. Resulting in increased risk of childhood obesity. There exist few notable limitations to these analyses, for instance, the selection of cross-educational research design that limits the confident casual inference. Other limitations of the study lie with the size of the sample included in the study in order to collect data. Limited sample size representing the limited geographical area could be a source of developing limitation for the study. The accuracy of results may also reduce due to possible integration of mother or fathers involved in proxy-reporting for other parents. This research study possesses the strength of involvement of recent data and reflection of the results through using improved ways for executing survey procedures and collaborating respondents.

\section{Conclusion:-}

With the alarming expansion in the widespread presence of childhood obesity and overweight throughout the world and generally shifting social status, economic standards and changing lifestyles, it is crucial to explore the risk factors that are associated with obesity and its adverse outcomes in children. Using data collected in Jeddah, Saudi Arabia, based on a cross-sectional research design, this research paper explores the association of parent's employment, education and income level of a family with three different BMI level in children. It is identified in this research study that child obesity in Jeddah, Saudi Arabia, is associated with employed fathers, and unemployed mothers. It is also identified that if parents are not highly educated it will not affect the child BMI.

\section{Recommendations:-}

The findings of the current research study should result in executing more accurate and well-organized prevention, awareness and intervention programs for the prevalence of obesity in children that should assure improved and effective school education for students irrespective of socio-economic status and status of employment of parents of the obese children. This will also assure the possible lower risk of obesity for the future generations. Moreover, it is 
also recommended to initiate with the organization of preventive community and educational institution based programs that may include early childhood obesity activities and overcoming social health disparities. Through the successful execution of the current research study, researchers strongly encourage and stress about the importance of education, especially in parents. It is highly recommended that education level of parents should be considered as an important part not only for gaining higher economic status but for better wellbeing and development of children.

\section{References:-}

1. WHO. Obesity and overweight. Fact sheets June 2016; Available from http://www.who.int/mediacentre/factsheets/fs311/en/.

2. Al-Enazy, W. H., Al Dahi, S. K., \& Al Hariri, I. M. (2014). Prevalence of overweight and obesity among Saudi primary school students in Tabuk, Saudi Arabia. Saudi journal of obesity, 2(1), 13.

3. Al-Hazzaa, H. M. (2007). Prevalence and trends in obesity among school boys in Central Saudi Arabia between 1988 and 2005. Saudi medical journal, 28(10), 1569.

4. Goran, M. I., Ball, G. D., \& Cruz, M. L. (2003). Obesity and risk of type 2 diabetes and cardiovascular disease in children and adolescents. The Journal of Clinical Endocrinology \& Metabolism, 88(4), 1417-1427.

5. Sinha, R., Fisch, G., Teague, B., Tamborlane, W. V., Banyas, B., Allen, K.,\& Sherwin, R. S. (2002). Prevalence of impaired glucose tolerance among children and adolescents with marked obesity. New England journal of medicine, 346(11), 802-810.

6. Needham, B. L., \& Crosnoe, R. (2005). Overweight status and depressive symptoms during adolescence. Journal of Adolescent Health, 36(1), 48-55.

7. Anderson, P. M., \& Butcher, K. F. (2006). Childhood obesity: trends and potential causes. The Future of children, 19-45.

8. Sahoo, K., Sahoo, B., Choudhury, A. K., Sofi, N. Y., Kumar, R., \& Bhadoria, A. S. (2015). Childhood obesity: causes and consequences. Journal of family medicine and primary care, 4(2), 187.

9. Hassan, N. E., El-Masry, S. A., Farid, T., \& Khalil, A. (2016). Influence of Parental and Some Demographic Characteristics on Overweight/Obesity Status among a Sample of Egyptian Children. Open access Macedonian journal of medical sciences, 4(3), 342.

10. Lamerz, A., Kuepper-Nybelen, J., Wehle, C., Bruning, N., Trost-Brinkhues, G., Brenner, H., ... \& HerpertzDahlmann, B. (2005). Social class, parental education, and obesity prevalence in a study of six-year-old children in Germany. International journal of obesity, 29(4), 373-373.

11. Al-Saeed, W. Y., Al-Dawood, K. M., Bukhari, I. A., \& Bahnassy, A. (2007). Prevalence and socioeconomic risk factors of obesity among urban female students in Al-Khobar city, Eastern Saudi Arabia, 2003. Obesity Reviews, 8(2), 93-99.

12. Al-Isa AN, Moussa MA (1999) Factors associated with overweight and obesity among Kuwaiti kindergarten children aged 3-5 years. Nutr Health 13: 125-139. [13] Matthiessen, J., Stockmarr, A., Fagt, S., Knudsen, V. K. and Biltoft-Jensen, A. (2014), Danish children born to parents with lower levels of education are more likely to become overweight. Acta Paediatr, 103: 1083-1088. doi:10.1111/apa.12722

13. Matthiessen J1, Stockmarr A, Fagt S, Knudsen VK, Biltoft-Jensen A (2014) Danish children born to parents with lower levels of education are more likely to become overweight. Acta Paediatr 103: 1083-1088.

14. Biehl A, Hovengen R, Grøholt E-K, Hjelmesæth J, Strand BH, Meyer HE. Adiposity among children in Norway by urbanity and maternal education: a nationally representative study. BMC Public Health. 2013;13:842. doi:10.1186/1471-2458-13-842.

15. Moraeus L, Lissner L, Yngve A, Poortvliet E, Al-Ansari U, et al. (2012) Multi- level in uences on childhood obesity in Sweden: societal factors, parental determinants and child's lifestyle. Int J Obes (Lond) 36: 969-976

16. Mushtaq, Gull, Shahid, Sha que, Abdullah, et al. (2011) Family-based factors associated with overweight and obesity among Pakistani primary school children 16: 11-114.

17. Ball K, Mishra G. Whose socioeconomic statusinfluences a woman's obesity risk; her mother's, her father's, or her own? Int J Epidemiol. 2006; 35:131-138. http://dx.doi.org/10.1093/ije/dyi216 PMid:16284404

18. EL-bayoumyI, Shady I, Lotfy H. Prevalence of obesity among adolescents (10-14 years) in Kuwait. Asia Pac J Public Health. 2009;21:153-159. http://dx.doi.org/10.1177/1010539509331786 PMid:19190003

19. Gnavi R, Spagnoli TD, Galotto C, Pugliese E, Carta A, Cesari L. Socioeconomic status, overweight and obesity in prepuberal children= a study in an area of Northern Italy. Eur J Epidemiol 2000;16:797-803.

20. Anderson PM, Butcher KF, Levine PB. Maternal employment and overweight children. J Health Econ 2003;22:477-504. 
21. Hawkins T, Cole C. Law, Millennium Cohort Study Child Health Group. Maternal employment and early childhood overweight: findings from UK Millennium Cohort Study. Int J Obes (Lond). 2008; 32(1):30-38. http://dx.doi.org/10.1038/sj.ijo.0803682 PMid:17637703 PMCid:PMC2679151

22. Alam AA. Obesity among female school children in North West Riyadh in relation to affluent lifestyle. Saudi Med J 2008;29:1139-1144.

23. Amin TT, Al-Sultan AI, Ali A. Overweight and Obesity and their Association with Dietary Habits, and Sociodemographic Characteristics Among Male Primary School Children in Al- Hassa, Kingdom of Saudi Arabia. Indian J Community Med 2008;33:172-181.

24. Bussiness, A. Servant in Saudi Arabia. 2010 [cited 25/1/2010]; Available from: http://forum.illaftrain.co.uk/t17135/. 